Design and Method: Female SAMP8 $(\mathrm{n}=24)$ and SAMR1 $(\mathrm{n}=24)$ mice were divided in three groups: 3-, 6- and 10-months old. Mice were sacrificed and vascular rings (4 mm long) from thoracic aorta were mounted for isometric recording of tension in organ bath and concentration response curves for $\mathrm{U}-46619\left(10^{-9}\right.$ to $\left.10^{-6} \mathrm{M}\right)$ were performed in absence and in presence of indomethacin $\left(10^{-5} \mathrm{M}\right)$. A segment of thoracic aorta was immediately frozen for protein expression studies and a sample of blood was collected from each mouse before sacrifice.

Results: TXA2 receptor expression and maximal contraction to U46619 of SAMP8 aorta were markedly higher than in SAMR1 at 3-, 6- and 10-months old mice, indicating than senescence increases contractile response. The presence of indomethacin $\left(10^{-5} \mathrm{M}\right)$, a cyclooxygenase inhibitor, increased the maximal contraction to U-46619 in SAMR1 and SAMP8 aorta from 3-months old groups, suggesting the production of prostacyclin in young animals. By contrast, in 6-months old SAMR1 group, indomethacin decreased the sensitivity to U46619 and in 10-months old group decreased both the sensitivity and maximal contraction, indicating that aging induces a release of contractile prostanoids in aorta. These effects were significantly enhanced in aorta from SAMP8 of 6- and 10-months old mice. Plasma levels of estradiol did not change among female mice of the all groups.

Conclusions: The results reveal that senescence enhances contractile responses to TXA2 in aorta from female mice by increasing the synthesis and release of contractile prostanoids. This process occurs earlier in aortas from SAMP8 mice. As plasma estradiol levels were similar in all groups the increased synthesis of contractile prostanoids may be an effect related to aging. Supported by Ministerio de Ciencia e Innovación, ISCIII (FIS 10/00518, RED HERACLES RD06/0009); Conselleria de Sanidad, GV (AP131/10, AP-117/10 and GE-021/10).

\section{PP.6.155 ENDOTHELIAL DYSFUNCTION AND VITAMIN D STATUS IN ESSENTIAL HYPERTENSION. PRELIMARY RESULTS}

F. Tornese ${ }^{1}$, C. Scazzone ${ }^{2}$, R. Arsena ${ }^{1}$, L. Guarino ${ }^{1}$, A. Ocello ${ }^{1}$, A. Bono ${ }^{2}$, G. Cerasola ${ }^{1}, \mathrm{~S}$. Cottone $\mathrm{e}^{1}$. ${ }^{1}$ Dipartimento Di Medicina Interna E SpecialisticaUniversity of Palermo, Palermo-Italy, ${ }^{2}$ Dipar Di Biotecnologie Mediche E Medicina Legale. Sezione Di Biochimica Medica-University of Palermo, Palermo-Italy

Objective: The exact mechanism by which vitamin D3 deficiency may determine an increased cardiovascular risk has not yet been elucidated. The current ongoing study evaluates the possible relationships among vitamin D status, endothelial dysfunction and inflammation.

Design and Method: In 40 primary hypertensives (mean $47.3 \pm 12$ years mean blood pressure $137 / 97 \pm 20 / 24 \mathrm{mmHg}$ ) and having normal renal function (eGFR-MDRD: $90 \pm 19.6 \mathrm{ml} / \mathrm{min}$ ) plasma concentrations of 25 -hydroxyvitamin D3, parathormone (PTH), ICAM and VCAM (markers of endothelial dysfunction) high sensitivity PCR and TNF-alpha (markers of inflammatory activation), $24 \mathrm{~h}$ blood pressure were evaluated.

Results: 25-hydroxyvitamin D3 levels were deficient in all patients (mean $26.5 \pm 7 \mu \mathrm{g} / \mathrm{L}$, cut-off values $<30 \mu \mathrm{g} / \mathrm{L})$ and were inversely correlated with $\operatorname{ICAM}(r=-0.37, p=0.01), \operatorname{VCAM}(r=-0.35, p=0.02)$, hsPCR $(r=-0.35$, $\mathrm{p}=0.02)$, TNF-alpha $(\mathrm{r}=0.38, \mathrm{p}=0.01)$ and PTH levels $(\mathrm{r}=-0.42$, $\mathrm{p}=0.005)$.

Conclusions: These preliminary results show that vitamin D3 levels are reduced in hypertensives, although $\mathrm{PTH}$, calcium and phosphorus levels, and glomerular filtration rate were within normal range. Furthermore, these data suggest that low vitamin D3 levels are associated with endothelial dysfunction and with markers of inflammatory activation in patient with primary hypertension.

\section{PP.6.156 MICROALBUMINURIA AND ENDOTHELIAL DYSFUNCTION IN HYPERTENSIVE PATIENTS WITH METABOLIC SYNDROME}

M. O. Gonzalez Albarran, Sara Calvo, Marta Carrasco, Marta Cano, Gilberto Perez, Jesus Gomez. Hospital Ramon Y Cajal, Madrid-Spain

Objectives: To study the possible relationship between endothelial function and microlabuminuria levels in patients with hypertension and metabolic syndrome (MS).

Methods: We studied 28 hypertensive patients with MS, according to NCEPATPIII criteria. IR was estimated by HOMA index. The endothelial dysfunction was evaluated by brachial artery ultrasonographic (Echo Blaster 128; transductor 7.5 MHz), endothelial dependent-vasodilation(EDVD) was measured during reactive hyperaemia (\%change in the diameter of brachial artery after 1 min of hyperaemia). The endothelial independent-vasodilation (EIVD) was measured by the nitroglycerin ( $0.4 \mathrm{mg}$ sublingually) administrated after at least 10 minutes of rest following reactive hyperemia. The maximum vasodilation occurs three to four minutes after administration. Urinary albumin excretion was classified in normoalbuminuria $(<30 \mathrm{mg} / 24 \mathrm{~h}, \mathrm{n}=12)$, microalbuminuria between $30-300 \mathrm{mg} / 24 \mathrm{~h}, \mathrm{n}=14)$. According to OGTT $(75 \mathrm{~g})$, we divided into two groups: Patients with normal glucose tolerance (Fasting glucose $<100 \mathrm{mg} / \mathrm{dl}$ and $2 \mathrm{~h}$ glucose $<140 \mathrm{mg} / \mathrm{dl}$ ) (NG group $=8$ patients) and patients with abnormal glucose tolerance ( 9 subjects with glucose intolerance and 11 patients with type 2 diabetes).

Results: AG patients had more insulin resistance than subjects in NG group. Moreover, AG subjects were elderly $(67,2 \pm 4.5$ vs $46,8 \pm 5,6 ; p<0.05)$. Patients with microalbuminuria had more insulin resistance than patients with normoalbuminuria $(\mathrm{p}<0.05)$. Moreover, AG patients (with $\mathrm{DM})$ showed higher levels of microalbuminuria than those with NG $(\mathrm{p}<0.05)$. The percentages of change in EDVD and EIVD were: $19.54 \pm 12.5$ y $6.68 \pm 5.2$, respectively. In AG group $(n=20)$, the percentage of change in EDVD was lower $(10.1 \pm 6.2 \%)$ than NG group $(29.34 \pm 15 \%), p<0.05$. Patients with microalbuminuria had less EDVD $(9.8 \pm 4.9 \%$ vs $25.1 \pm 14$; p < 0.001$)$ than normoalbuminuria ones. A negative correlation between microalbuminuria levels and EDVD was found $(\mathrm{r}=-0.49 ; \mathrm{p}=0.007)$ and with insulin resistance measured by HOMA $(\mathrm{r}=-0.44 ; \mathrm{p}=0.019)$.

Conclusions: in our hypertensive patients with metabolic syndrome, microalbuminuria is associated with more insulin resistance, more glycemic abnormalities and more endothelial dysfunction.

\section{PP.6.157 HAEMOSTASIS PARAMETERS DISTURBANCES IN HEALTHY INDIVIDUALS WITH HIGH NORMAL BLOOD PRESSURE}

A. Kotrotsou, D.P. Papadopoulos, I. Mourouzis, A. Dellaportas, M. Bonios, I. Vlahodimitris, P. Kribas, C. Ekonomou. Esh Excellent Center HypertensionLaiko University Hospital, Athens- Greece

High normal blood pressure(HNBP) seems to be related to increased cardiovascular risk in healthy normotensive subjects, while essential hypertension is associated with haemostasis balance disturbances. Aim of our study was to examine the impact of HNBP on haemostasis parameters in healthy individuals with HNBP and to compare the findings to those of healthy normotensives(HN) with normal blood pressure (BP) levels. Two hundred-four (96 M, $108 \mathrm{~F}) \mathrm{HN}$, mean age $57 \pm 7$ years and Body Mass Index (BMI) $23 \pm 1.6 \mathrm{Kg} / \mathrm{m}^{2}$ were studied. Systolic and diastolic (SBP, DBP) blood pressure were measured. Serum fibrinogen $(\mathrm{F})$, thrombomodulin $(\mathrm{TM})$, and the antigens of plasminogen activator inhibitor-1 (PAI-1 Ag) and tissue plasminogen activator (tPA-Ag) were determined in the whole population. Eighty-eight (46 M, 42 F) subjects had HNBP, (Group A) and 136 (70 M, 66 F) (Group B) had normal BP. The two groups were matched for age, sex, BMI.

Subjects with HNBP had significantly higher F $(300 \pm 50$ vs. $280 \pm 40 \mathrm{mg} / \mathrm{dl}$ $\mathrm{p}<0.1)$ TM $(6.5 \pm 0.7 \mathrm{vs} .6 \pm 0.8$ IU/ML p < .001).PAI-1 Ag $(8.5 \pm 1.3$ vs. $7.8 \pm 0.7 \mathrm{mg} / \mathrm{dl} \mathrm{p}<0.01)$ and tPA-Ag $(22 \pm 10$ vs. $18 \pm 11 \mathrm{ng} / \mathrm{dl} \mathrm{p}<0.1)$ levels compared with subjects with NBP.

Conclusions: Our findings indicate that high normal blood pressure is associated with haemostasis disturbances predisposing to hypercoagulability and impaired fibrinolysis. This observation may be of prognostic value for future cardiovascular events in this group and needs further investigation.

\section{PP.6.158 ENDOTHELIAL FUNCTION DYNAMICS UNDER THE INFLUENCE OF DIFFERENT VASOACTIVE ANTIHYPERTENSIVE AGENTS}

O. Fedorishina ${ }^{1}$, K. Protasov $^{1}$, A. Dzizinsky ${ }^{1}$, E. Trunova ${ }^{2}$, M. Makarenko ${ }^{2}$, N. $\mathrm{Gakh}^{2} .{ }^{I}$ Institute of Advanced Medical Studies, Irkutsk-Russia,

${ }^{2}$ Medical-Diagnostic Center, Angarsk-Russia

Aim: To investigate and compare the endothelium-dependent vasorelaxation dynamics when administering beta-blockers carvedilol, nebivolol and calcium antagonist amlodipine to patients with essential arterial hypertension $(\mathrm{AH})$

Material and Methods: Ninety patients with 1-2 grades AH aged 30-55 years were studied. All patients were randomized to receive carvedilol $(n=45)$, nebivolol $(n=25)$ and amlodipine $(n=25)$ in initial daily doses of 25,5 and $5 \mathrm{mg}$ respectively. In two weeks if office BP level of $140 / 90 \mathrm{mmHg}$ was not attained the dose of medicine was doubled. In four weeks in cases of uncontrolled $\mathrm{AH}$ the 